\title{
Management of neonatal posterolateral diaphragmatic hernia
}

\author{
UNNIKRISHNAN R NAIR, ANTHONY ENTRESS, DUNCAN R WALKER \\ From the Regional Centre for Paediatric Cardiothoracic Surgery, Killingbeck Hospital, Leeds
}

ABSTRACT From March 1978 to April 198213 neonates with a left posterolateral diaphragmatic hernia were seen in respiratory distress within 12 hours of birth. Each had severe acidosis and hypoxia. They were immediately intubated and ventilated. Arterial and central venous lines were inserted, the acidosis was partially corrected, and a dopamine infusion of $4-8 \mu \mathrm{g} / \mathrm{kg} / \mathrm{min}$ was begun immediately. Continuous monitoring of arterial and venous pressures, core and skin temperatures, blood gases, and $\mathrm{pH}$ was instituted. Diaphragmatic defects were repaired by direct suture in nine neonates and by Gore-Tex patches in four. The left lung in all patients was hypoplastic. Ventilation and inotropic support were continued for four to five days after operation and close control of acid-base balance was maintained. All but one survive and are doing well. We consider the key to survival to be management of the dangerous combination of acidosis (by enhancing peripheral and renal perfusion with dopamine) and hypoxia (by prolonged assisted ventilation).

The incidence of congenital diaphragmatic hernia in Britain in 1958 was about one in 2200 births. $^{1}$ Thirty-five per cent of all affected neonates were stillborn and $95 \%$ of these had other major congenital abnormalities. Twenty per cent died within one hour of birth and the diagnosis was seldom made before postmortem examination. Other major congenital abnormalities were rare in those surviving more than one hour. ${ }^{12}$ The current mortality rate for neonates with diaphragmatic hernia seen within 24 hours of birth remains high (25-50\%) despite the rarity of associated congenital abnormalities and the technical success of operative repair in most instances. ${ }^{3}$ Earlier diagnosis and transfer to a major centre have improved survival but the figures remain poor. Better results have been obtained in those infants seen after the first 24 hours, ${ }^{45}$ for whom the long-term prognosis is excellent after successful repair of the hernia. ${ }^{67}$

In infants with posterolateral diaphragmatic hernia pulmonary hypoplasia is usually severe on the side of the hernia and less severe on the other side. ${ }^{89}$ Severe bilateral hypoplasia, which is fatal, occurs

Address for reprint requests: Mr DR Walker, Killingbeck Hospital, York Road, Leeds LS14 6UQ.

Accepted 21 January 1983 occasionally. Several authors have noted that neonates who survive operation often improve dramatically at first but subsequently deteriorate with increasing hypoxaemia and die. ${ }^{3410}$ The initial improvement indicates that pulmonary hypoplasia is probably not the primary cause of death. An increase in pulmonary vascular resistance and shunting of blood away from the lungs through a persisting "fetal" circulation have been shown in these patients ${ }^{11}$ and may be the mechanism leading to clinical deterioration with increasing hypoxaemia.

Infants with a congenital diaphragmatic hernia requiring operation within 24 hours of birth are usually considerably hypoxic and acidotic at the time of diagnosis. Hypoxia and acidosis both cause pulmonary vasoconstriction ${ }^{12-14}$ and thus favour the persistence of a fetal-type circulation with right-to-left shunting. It has been shown in adults ${ }^{13}$ and in newborn calves ${ }^{14}$ that if the hydrogen-ion concentration of the blood is maintained at near-normal values ${ }^{3} 15$ hypoxia produces only minor changes in the pulmonary vasculature, whereas it causes appreciable pulmonary vasoconstriction in the presence of acidosis. This research suggests that a disastrous condition may be prevented if the acid-base balance is carefully controlled in affected infants.

Hypoxia and acidosis also cause myocardial depression and peripheral vasoconstriction, which 
lead to poor tissue perfusion and consequently to anaerobic metabolism and metabolic acidosis. The acidosis can be controlled by repeated buffering with sodium bicarbonate or trihydroxymethylaminomethane and by increasing peripheral perfusion with an inotropic agent.

This paper reports on the management of infants with congenital diaphragmatic hernia seen within 24 hours of birth and on the use of dopamine for this condition. By increasing peripheral perfusion and dilating the renal vasculature dopamine helps to control acidosis. Thus it limits pulmonary vasoconstriction ${ }^{16}$ and hypoxaemia, the vicious circle which if uncontrolled may lead to death.

\section{Methods}

From March 1978 to April 198213 infants with congenital posterolateral diaphragmatic hernia were transferred to the regional centre for paediatric cardiac surgery at Killingbeck Hospital, Leeds. All were in considerable respiratory distress and required initial resuscitation followed by surgical repair of the hernia within 12 hours of birth. Birth weights ranged from 2.5 to $3.8 \mathrm{~kg}$ (mean $3.2 \mathrm{~kg}$ ). All had a left-sided posterolateral diaphragmatic hernia. Eight infants required intubation and ventilation before transfer from the referring hospital, the other four managing with spontaneous respiration with $100 \%$ oxygen. All were transferred in an incubator and all had a nasogastric tube in situ.

Preoperative resuscitation was continued in the intensive care unit. Positive-pressure ventilation was started or continued through an endotracheal tube. Arterial lines (radial or brachial), central venous pressure lines (internal jugular), and rectal and skin temperature probes were inserted and connected to continuous monitoring equipment. Regular blood gas and $\mathrm{pH}$ measurements were begun and acidosis was partially corrected with $4.2 \%$ sodium bicarbonate.

A dopamine infusion (4-8 $\mu \mathrm{g} / \mathrm{kg} / \mathrm{min})$ was begun as soon as the central venous line was inserted and the dose adjusted according to the response. Skin temperature changes were good indicators of improvement or deterioration. Great care was taken to maintain a normal core temperature. Broadspectrum antibiotics were administered.

When optimum improvement was considered to have occurred (one to three hours after admission) the infant was transferred to the adjacent operating theatre. The average age at operation was 8 hours. A left lateral thoracotomy through the eighth intercostal space was used in each procedure. There was some difficulty in reducing the bowel in most infants: in one a pack had to be inserted in the abdomen and retrieved through a small laparotomy. Nine diaphragmatic defects were repaired by direct suture, but in four patients the defect was too large for direct suture and a Gore-Tex (polytetrafluoroethylene) patch was used. In all infants the left lung was hypoplastic and in eight the hypoplasia was considered severe. After repair of the diaphragm the chest was closed with a single intercostal drain.

Postoperative respiratory and circulatory support was required in all infants. Intermittent positivepressure ventilation was continued for two to eight days (mean 5.3 days). The concentration of inspired oxygen was adjusted to maintain the partial pressure of arterial oxygen $\left(\mathrm{PaO}_{2}\right)$ at about $8 \mathrm{kPa}$. High oxygen tensions were often required to achieve this value and accurate monitoring was essential to prevent oxygen-induced pulmonary damage and a further block to gaseous diffusion. Inflation pressures were carefully controlled and $25-30 \mathrm{~cm}$ of water was set as a maximum. All infants were weaned from intermittent positive-pressure ventilation through either intermittent mandatory ventilation or a continuous positive-pressure airway circuit and all achieved spontaneous ventilation. Regular physiotherapy day and night was necessary to remove secretions, prevent contralateral atelectasis, and encourage maximum expansion of the ipsilateral lung.

The dopamine infusion was continued until the infants were past the danger period, as judged by improvement in ventilatory capacity. This was usually on the third or fourth postoperative day. Weaning from dopamine was very gradual. A $5 \%$ dextrose solution was used to maintain adequate hydration and central venous pressure was watched for any fall, which was taken as an indication for more plasma or blood depending on the haematocrit. Sputum cultures were checked daily.

The greatest care was taken throughout to determine the cause (which was usually respiratory) of any deterioration in indices of vital functions, blood gases, or acid-base balance and to apply energetic corrective measures (for example, endotracheal suction and physiotherapy). Adjustments in the rate of the dopamine infusion were often necessary at times of crisis. Repeated buffering with sodium bicarbonate $(4.2 \%)$ was sometimes necessary, but dosage was kept to a minimum because of the high sodium content of the solution and the risk of myocardial failure with overtreatment.

\section{Results}

Several complications developed in the postoperative period. The most serious was inadequate venti- 
lation in one infant, caused by dried secretions that blocked the endotracheal tube. His condition improved immediately after the tube was changed. Several babies had pulmonary atelectasis, and energetic physiotherapy was required to achieve re-expansion. Three infants had an uneventful recovery and were extubated on the second postoperative day. The others all had episodes of hypoperfusion and hypoxaemia, which were detected early by continuous monitoring and effectively treated. All but one survive and continue to progress satisfactorily. The child who died was a boy weighing $2 \mathrm{~kg}$ who was born with an Apgar score of 2 . He was intubated and vigorously resuscitated but had a cardiac arrest and required cardiac massage before transfer to us. On admission the $\mathrm{pH}$ of his blood was $6 \cdot 8$. He was again resuscitated and taken to the operating room, where a satisfactory repair was achieved. His condition stabilised but some four hours after operation he developed disseminated intravascular coagulopathy and died of intracerebral haemorrhage eight hours after operation.

\section{Discussion}

Infants with congenital diaphragmatic hernia requiring operation within 24 hours of birth usually have considerable respiratory and metabolic acidosis at the time of diagnosis. A decade ago the mainstay of treatment was immediate operation to reduce the abdominal contents back into the peritoneal cavity, thus relieving mediastinal displacement and allowing some expansion of the associated hypoplastic lung. This policy was associated with a low survival rate (about $25-30 \%$ ), many infants dying at the time of operation or within 24 hours after it. Adequate preoperative resuscitation and postoperative intensive care have improved survival but the mortality rate is still an unacceptable $25-30 \%$.

Most postoperative deaths in infants with posterolateral diaphragmatic hernia are related to pulmonary vasoconstriction combined with myocardial failure. Pulmonary vasoconstriction is the fetal homeostatic mechanism that directs blood away from the lungs to the placenta and other vital organs and this response of the pulmonary vasculature to hypoxia and acidosis persists in the neonate. In the last few years several authors have documented the persistence of a fetal-type circulation in infants with posterolateral diaphragmatic hernia, with right-toleft shunting through a persistent ductus arteriosus, foramen ovale, and intrapulmonary channels. ${ }^{3410}$ This shunting, which is secondary to the high pulmonary vascular resistance, was shown to be reversible in many instances. Anatomical and histological support for a right-to-left shunt is available. Post- mortem examinations of patients with congenital diaphragmatic hernia regularly show a large patent ductus arteriosus and histological examinations of the lungs show that there is more smooth muscle in the small pulmonary arteries than in those of matched controls. ${ }^{17}$ Physiologically, evidence for right-to-left shunting in these infants comes from the appreciable $\mathrm{PaO}_{2}$ differences between arterial samples taken simultaneously from a radial artery and the descending thoracic aorta. ${ }^{4}$ Clinically, it is important to abolish or at least minimise this shunt. Ductus ligation has been tried but the results have been poor. ${ }^{4}$ Prolonged extracorporeal membrane oxygenation has proved equally unsuccessful. ${ }^{18} \mathrm{~A}$ direct attack on the pulmonary hypertension with pulmonary vasodilator drugs (morphine, acetylcholine, tolazoline, and chlorpromazine hydrochloride) has also been tried and has produced a few survivors among infants otherwise pursuing a fatal postoperative course with progressive anoxia. 4101920

We consider that the key to survival lies in the management of the dangerous combination of acidosis and hypoxia. Our experience in congenital heart operations has shown that if acidosis is controlled hypoxia is tolerated remarkably well. We attempt to minimise acidosis by enhancing peripheral and renal perfusion with dopamine and to limit hypoxia by prolonged assisted ventilation. Dopamine at doses of $2-10 \mu \mathrm{g} / \mathrm{kg} / \mathrm{min}$ encourages peripheral perfusion by its positive inotropic effect and acts as a peripheral vasodilator, thereby reducing the degree of anaerobic metabolism. It specifically enhances renal perfusion and thereby acid-base regulation by the kidney. ${ }^{21-24}$ Dopamine has been reported to be a safe drug at doses below $10 \mu \mathrm{g} / \mathrm{kg} / \mathrm{min}$, the only side effects being nausea and vomiting. ${ }^{25}$ Extreme caution must be used with larger doses because severe vasoconstriction can lead to gangrene. ${ }^{26}$

The importance of prolonged respiratory support has been emphasised. ${ }^{27}$ We recommend that all infants with impaired respiratory function should be ventilated for a minimum of 48 hours and usually longer. Weaning from mechanical ventilation should be gradual and a return to full respiratory support for a further period is frequently necessary. The adequacy of ventilation is judged by regular arterial blood gas estimations, which should be obtained from a cannula placed proximal to the ductus because shunting at this level may influence distal blood gas pressures.

Respiratory complications occur commonly in the postoperative period. Contralateral pneumothorax has been reported frequently and a chest radiograph is essential when any deterioration occurs. Contralateral chest drainage has been advocated 
because of the high mortality when this condition is not recognised. ${ }^{5}$ We have not experienced this problem in our series and attribute this to good anaesthetic management.

Some authors haved used respiratory function criteria (partial pressure of arterial oxygen and carbon dioxide, alveolar arterial oxygen pressure difference) to predict survival in neonates with a congenital diaphragmatic hernia. ${ }^{1528}$ We attach little importance to these criteria as we have shown that poor-risk infants can survive. We do accept, however, that there is a small group of infants with congenital diaphragmatic hernia in whom the bilateral pulmonary hypoplasia is so severe as to be incompatible with life.

Early diagnosis, efficient resuscitation, and maximum cardiorespiratory support can considerably reduce the mortality of infants with large congenital diaphragmatic hernias. The dangerous combination of acidosis and hypoxia can be effectively mangaged by a dopamine infusion $(4-8 \mu \mathrm{g} / \mathrm{kg} / \mathrm{min})$ and prolonged respiratory support, and this treatment is best organised in a special unit where the patients can be closely monitored by staff experienced in neonatal thoracic surgery and intensive care.

\section{References}

'Butler N, Claireaux AE. Congenital diaphragmatic hernia as a cause of perinatal mortality. Lancet 1962;i:659-63.

${ }^{2}$ Harrison MR, Bjordal RI, Langmark F, et al. Congenital diaphragmatic hernia: the hidden mortality. $J$ Pediatr Surg 1978;13:227-30.

${ }^{3}$ Dibbins AW. Congenital diaphragmatic hernia, hypoplastic lung and pulmonary vasoconstriction. Clin Perinatol 1978;5:92-104.

${ }^{4}$ Collins DL, Pomerance JJ, Travis $\mathrm{KW}$, et al. A new approach to congenital posterolateral diaphragmatic hernia. J Pediatr Surg 1977;12:149-56.

${ }^{5}$ Lewis MAH, Young DG. Ventilatory problems with congenital diaphragmatic hernia. Anaesthesia 1969; 24:571-80.

${ }^{6}$ Grotte G, Bjure J, Bratteby L, et al. Posterolateral diaphragmatic hernia: long-term results. Prog Pediatr Surg 1977;10:35-44.

' Landau LI, Phelan PD, Gillam GL, et al. Respiratory function after repair of congenital diaphragmatic hernia. Arch Dis Child 1977;52:282-6.

${ }^{8}$ Areechon W, Reid L. Hypoplasia of lung with congenital diaphragmatic hernia. Br Med J 1963;i:230-3.
${ }^{9}$ Kitagawa K, Hislop A, Boyden EA, et al. Lung hypoplasia in congenital diaphragmatic hernia. $\mathrm{Br} J$ Surg 1971;58:342-6.

${ }^{10}$ Moodie DS, Telander R, Kleinberg F, et al. Use of tolazoline in newborn infants with diaphragmatic hernia and severe cardiopulmonary disease. $J$ Thorac Cardiovasc Surg 1978;75:725-9.

1 Rudolph AM. Foetal and neonatal pulmonary circulation. Annu Rev Physiol 1979;41:383-95.

12 Bergofsky EH, Lehr DE, Fishman AP. The effect of changes in hydrogen ion concentration on the pulmonary circulation. J Clin Invest 1962;41:1492-502.

${ }^{13}$ Enson Y, Guitini C, Lewis ML, et al. The influence of hydrogen ion concentration and hypoxia on the pulmonary circulation. J Clin Invest 1964;43:1146-62.

${ }^{14}$ Rudolph AM, Yuan S. Response of the pulmonary vasculature to hypoxia and $\mathrm{H}+$ ion concentration changes. J Clin Invest 1966;45:399-411.

${ }^{15}$ Boix-Ochoa J, Natal A, Canals J, et al. The important influence of arterial blood gases on the prognosis of congenital diaphragmatic hernia. World J Surg 1977;11:783-7.

${ }^{16}$ Fiddler GI, Chatrath RR, Williams GJ, et al. Dopamine infusion for the treatment of myocardial dysfunction associated with a persistent transitional circulation. Arch Dis Child 1980;55:194-8.

${ }^{17}$ Naeye RL, Shochat JS, Whitman V, et al. Unsuspected pulmonary vascular abnormalities associated with diaphragmatic hernia. Pediatrics 1976;58:902-6.

${ }^{18}$ German JC, Gazzaniga AV, Raynar A, et al. Management of pulmonary insufficiency in diaphragmatic hernia using extracorporeal circulation with a membrane oxygenator. J Pediatr Surg 1977;12:905-12.

${ }^{19}$ Dibbins AW, Weiner ES. Mortality from neonatal diaphragmatic hernia. J Pediatr Surg 1974;9:653-62.

${ }^{20}$ Dibbins AW. Neonatal diaphragmatic hernia: a physiological challenge. Am J Surg 1976;131:408.

${ }^{21}$ Anonymous. Dopamine in cardiac failure and shock. $\mathrm{Br}$ Med J 1977;ii:1563-4.

22 Anonymous. Intravenous dopamine. Lancet 1977;ii: 231-2.

${ }^{23}$ Goldberg LI, Msieh YY, Resnekor L. Newer catecholamines for the treatment of heart failure and shock: an update on dopamine and a first look at dobutamine. Prog Cardiovasc Dis 1977;19:327-40.

${ }^{24}$ Mennie AT, ed. Dopamine hydrochloride: proceedings of an international symposium held at the Royal Society of Medicine by Arnar-Stone Laboratories, 30 June, 1976. Proc $R$ Soc Med 1977;70, suppl 2.

${ }^{25}$ Driscoll DJ, Gillette PC, McNamara DG. The use of dopamine in children. J Pediatr 1978;92:309-14.

${ }^{26}$ Stetson JB, Reading GP. Avoidance of vascular complications associated with the use of dopamine. Can Anaesth Soc J 1977;24:727-33.

${ }^{27}$ Boles ET, Schiller M, Weinberger M. Improved management of neonates with congenital diaphragmatic hernia. Arch Surg 1971;103:344-9.

${ }^{28}$ Raphaely RC, Downes JJ. Congenital diaphragmatic hernia: prediction of survival. J Pediatr Surg 1973;8:815-23. 